\title{
From Basic Wound Healing to Modern Skin Engineering
}

\author{
L.C. Andersson, H.C. Nettelblad and G. Kratz
}

\section{Introduction}

The skin is our largest organ and it simultaneously fulfills many functions required in everyday life. The most important function of the skin is to act as a barrier between the body and the external environment. Many immune cells are also present in the skin to provide protection against invading micro-organisms. The skin is in addition an important participant in the physiological water homeostasis and it is one of the main ways the body regulates its temperature. Normal skin has sensation with protective value; a physical tensile capacity allowing for body mobility and it provides the external contour as well as the texture and the color of the exterior.

Over the millennia mankind has been fascinated by the body's ability to heal itself. Throughout history the main goal has always been to cover skin defects and to close wounds in order to protect the human body. Skin grafting and flap surgical procedures have been used in order to facilitate wound healing for thousands of years. Due to the advances in critical care and resuscitation, patients who, in the past, would have died in the acute phase are now surviving. Consequently there is a much greater need for high-quality skin substitutes. The clinical demand has driven newer technologies, building upon principles learned using cadaver and autografts, to the creation of engineered skin substitutes using living allograft cells as well as the combining of technologies to create composites - the most advanced products and at present the closest products to living skin. An autologous split thickness skin graft currently still remains superior to all commercially available skin substitutes with regards to its unique qualities. There are, however, situations where we prefer to use non-autologous substitutes, either because the patient may be too fragile for the added surgical trauma of harvesting split-skin grafts or due to the fact that there is not enough skin which could be harvested, for example, post-burn.

\section{Structure of the Skin}

The skin consists of two principal layers: the epidermis and the dermis. The epidermis consists of a keratinized layer with no vital cells and cell layers of keratinocytes which produce keratin. The epidermis provides protection against micro-organisms and loss of fluids. The epidermis within the basal cell layer contains melanocytes that produce melanin, our skin pigmentation. The dermis mainly consists of fibroblasts and interstitial connective tissue. The fibroblasts produce collagen and elastine, which provide the tensile strength of the skin composite. The dermis also harbors hair follicles, which are lined by epidermal cells and are localized adjacent to sebaceous glands, which produce sebum. There are also sweat glands, blood vessels, and nerves in the dermis (Figure 6-1). The dermis provides the tensile strength and elasticity that allows mobility of the skin. ${ }^{1}$

\section{Historical Overview}

Our ancestors struggled to treat wounds and defects inflicted either by nature or by acts of man. Skin substitutes in the form of xenografts 


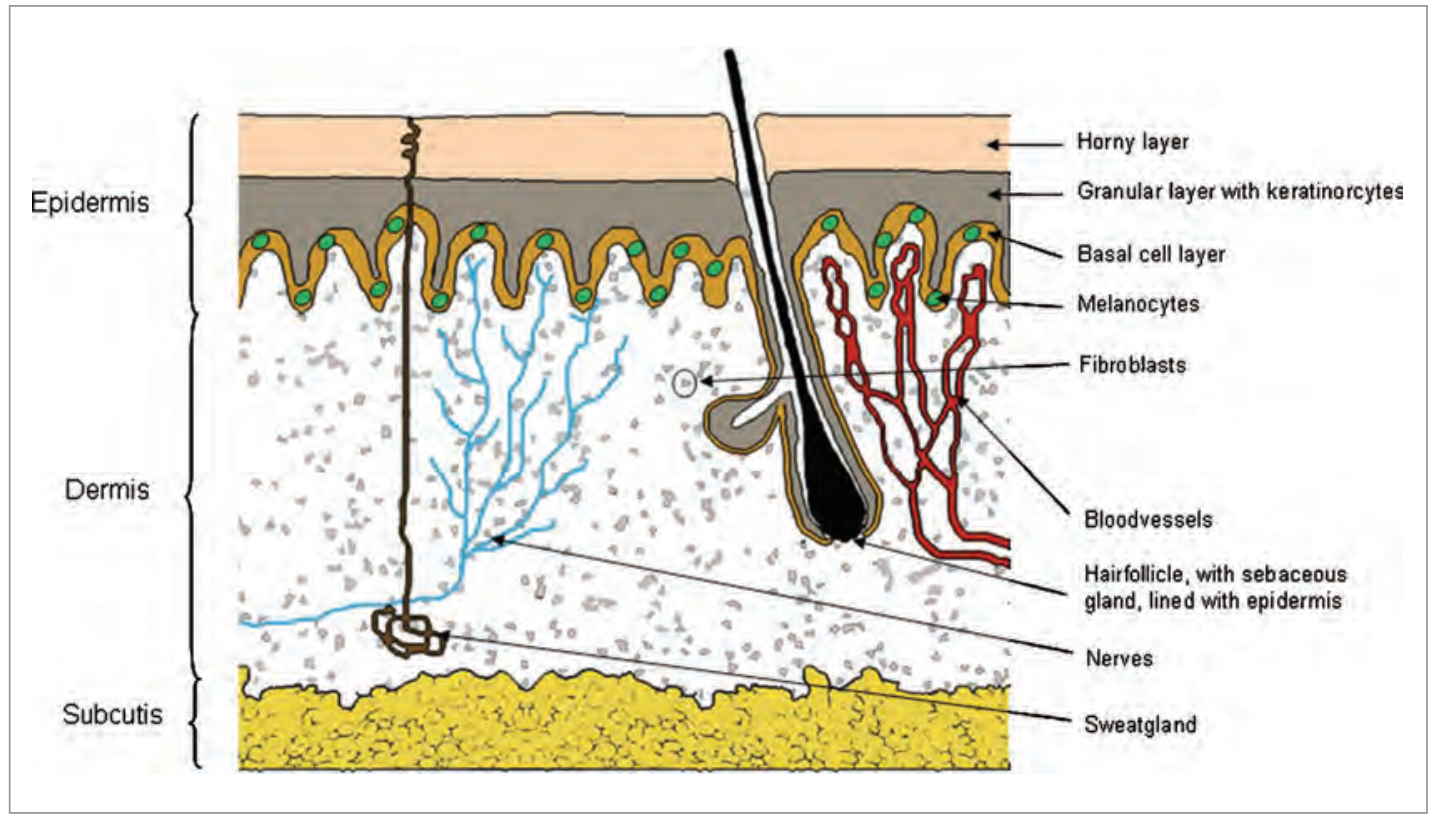

Figure 6-1. The skin in cross section.

were first used to provide wound coverage as far back as 1500 BC (frog skin). In the 1600s, lizard skin was used in western cultures and this progressed to the use of mammalian skins as well as cadaver skin during the twentieth century, including dog and rabbit skin and the still-used pigskin products. ${ }^{2-4}$ Facial deformities such as defects after the amputation of the nose were the type of problems that received the most attention. A famed practitioner, Sushruta (circa 600 $\mathrm{BC}$ ), described operations for reconstruction of the nose without any form of anesthesia. Tissue from the forehead was dissected but remained attached to the area between the eyebrows and was then turned down in order to reconstruct a nose and left intact for 3-4 weeks. The nasal bridge was then divided and the nose was improved in its shape. It was further described that the donor defect in the forehead healed rather well and left very little deformity. ${ }^{5}$ During the Roman Empire, Celsus (25 BC-50 AD) raised smaller flaps which involved the skin and the fat (pieces of skin and fat, with blood circulation still attached to the body in at least one area) in order to reconstruct skin defects in facial areas. ${ }^{6}$ Over the years, many others have contributed to new techniques and variations involving different types of flaps in order to correct defects with, but it was not until the beginning of the nineteenth century that the concept of skin grafting (auto grafting: a skin piece from one part of the body was cut loose with no attachment and no circulation, then grafted onto a well-vascularized wound on the same individual) became clinically used. Sir Astley Cooper removed skin from an amputated thumb and used it to cover the stump defect with as a fullthickness skin graft in $1817 .^{7}$ Nevertheless, skin grafting was not fully recognized and accepted for clinical use until the last quarter of the nineteenth century. In 1869, Reverdin reported that the healing of granulating wounds was improved by so-called "epidermic grafts". ${ }^{8}$ In 1874 , Thiersch advocated the use of larger sheets of epidermal grafts to cover wounds with and also emphasized the importance of an epidermal component in the graft with a small amount of dermis (Figure 6-2). The grafts used were thin split thickness skin grafts containing both the epidermis and the parts of the dermis and these pieces of skin were tangentially excised and grafted onto wounds and skin defects. The actual donor sites were then left to heal spontaneously through epithelialization from the depth and from the sides of the donor defect, which was itself superficial enough and the healing would be achieved in approximately 2 weeks. ${ }^{9}$ Xenografts gave way to homografts in 


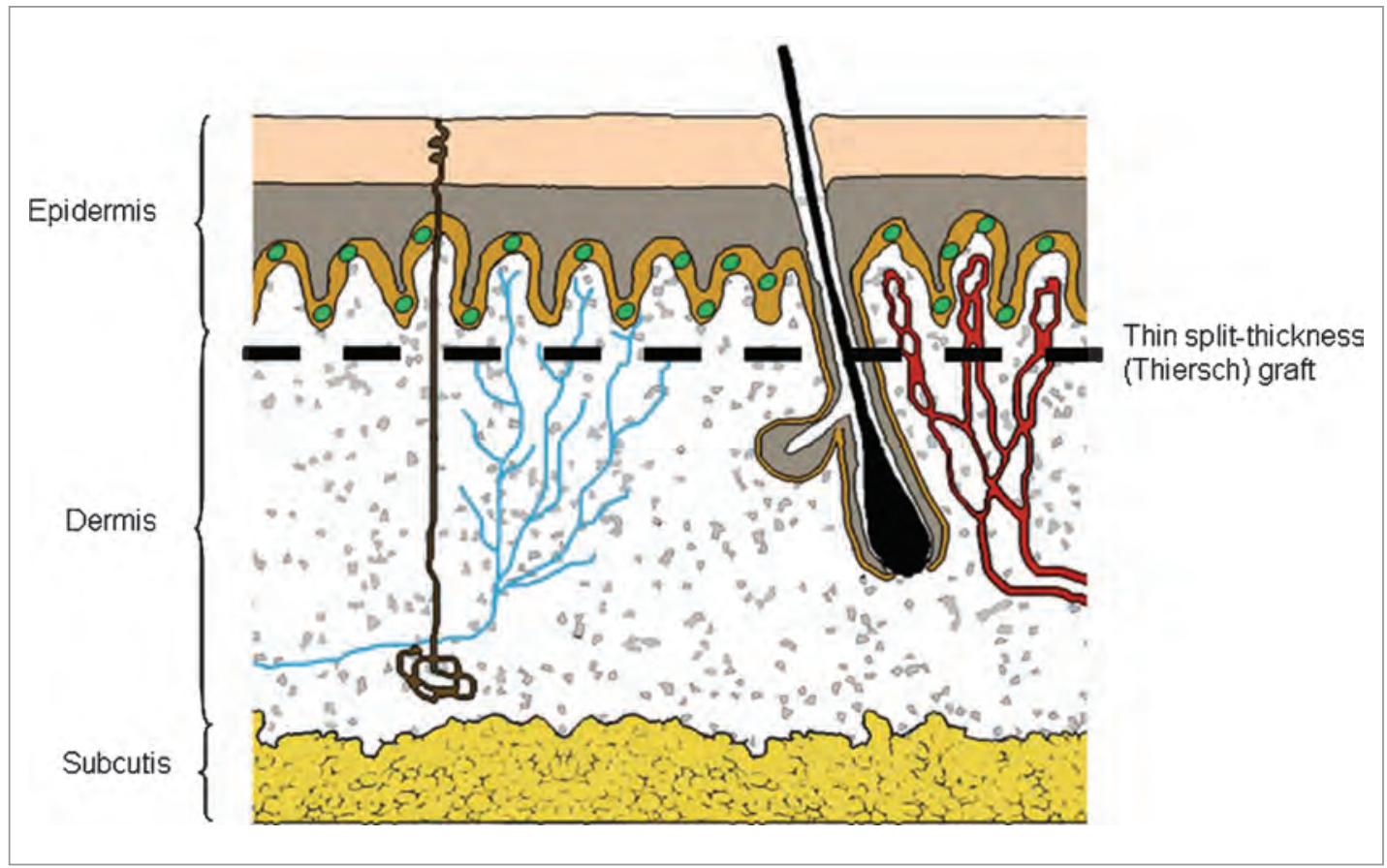

Figure 6-2. The skin in cross section - indicating the depth of a Thiersch graft.

the form of allograft (cadaveric graft) and autograft. The modern development of intensive care and improved surgical techniques enabled skin and fat flaps to be developed further into tissue flaps involving, e.g., skin, fat, tendon, muscle, and bone tissue. The tissue could be harvested in one part of the body and transferred to another body region in order to cover wounds with. The blood supply after having been disconnected at the original site was re-established via microsurgery. Many other developments in modern medicine also contributed to the overall need for larger wound areas to be covered with skin, e.g., burns and trauma ${ }^{10}$ Our increased understanding of immunology and wound healing has also been a contributing factor of great importance in modern wound management. The clinical demand of skin has driven the bio-engineering of skin, in the form of skin substitutes and skin cultivation, which will be integrated, more and more into clinical practice in the future. ${ }^{11}$

\section{Wound Healing}

The body will immediately respond with an acute inflammation if the skin is acutely damaged. Many physiological substances are released at this stage in order to initiate the normal wound-healing process. Granulation tissue of fibroblasts and new capillaries will grow into the wound. Collagen will be produced to provide stability and strength and an epithelialization from the wound edges will start. There are many factors that contribute to a normal wound-healing process and many others, which disturb this important process. An acute wound may not progress in the normal woundhealing process and instead become chronic. The understanding of wound healing constantly increases and many new treatments which facilitate wound healing are continuously being developed. ${ }^{9}$

\section{Epidermal Wound Healing}

The epidermal cells divide and migrate if damage to the epidermis has occurred. A wound no deeper than after the harvest of a split-skin graft (Figure 6-3) will heal spontaneously (epithelialization) if no infection arises, usually within 2-3 weeks with the correct type of wound dressing which protects from external bacteria, viruses, and particles. Damage to the epidermis does not normally result in 


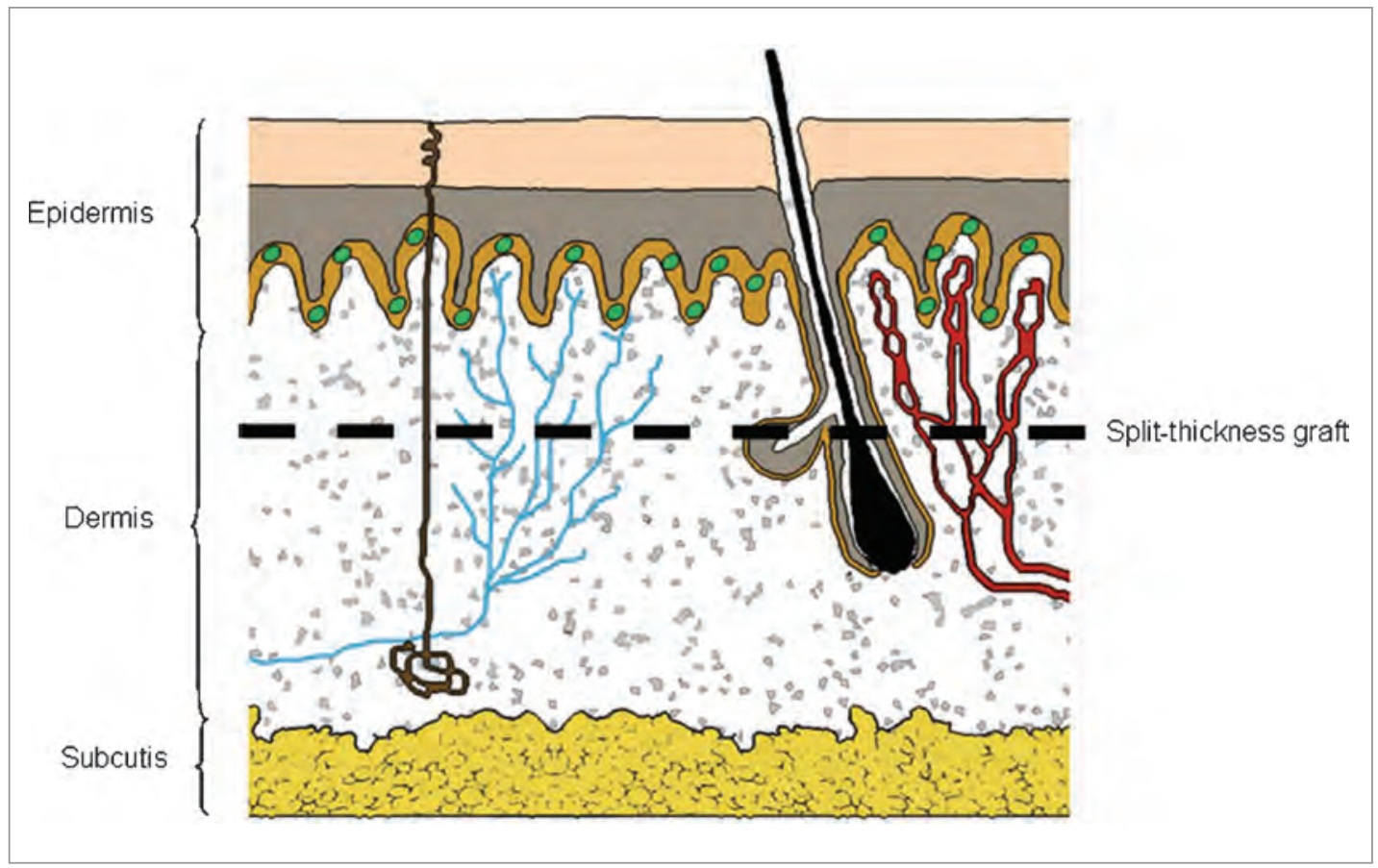

Figure 6-3. The skin in cross section -indicating the depth of a split-thickness graft.

contractive scarring but some pigmentation variation may be seen as a long-term result. The healing of the epidermis will proceed both from the wound edges as well as from the underlying tissues since there are keratinocytes which line the hair follicles. It can take several years for the basal cell membrane to remodel and for the melanocytes to migrate into the damaged area. ${ }^{9}$

\section{Dermal Wound Healing}

The healing of a wound, which extends deep down into the dermis, at the same depth as when a full-thickness skin graft is harvested, will take a lot longer than the healing of an epidermal superficial wound (Figure 6-4). There will be no epithelialization from the deeper tissues due to lack of keratinocytes in these planes, but healing takes place solely from the wound edges. Before the epithelialization from the wound edges can take place, a layer of granulation tissue consisting of fibroblasts and capillaries will form in order to reinstitute the dermis. The actual epithelialization from the wound edges will then spontaneously start on top of the granulation tissue. The wound should decrease by $10-15 \%$ of the original size per week in order to represent normal wound healing. ${ }^{12}$ The actual healing time of deep dermal or deeper tissue wounds will vary, all depending on the size of the wound and external interfering factors, e.g., foreign bodies, micro-organisms, and the patients' general condition. Large dermal wounds may need surgical intervention with debridements and skin grafting in order to heal. The dermal fibroblasts will produce collagen and scar tissue will form. The scar tissue in the dermis will over time be remodeled, but the scarred skin will contract and become less flexible and smoother than normal skin is. The dermal tensile strength may also be reduced in scarred skin. The skin mobility in scarred skin after dermal healing will be reduced and skin scar contractions may have to be surgically "released" or corrected in order to improve the function of a specific area of the body. The scarred skin after damage to the dermis also appears different in pigmentation than an individual's normal skin. The whole maturing process of a dermal scar can take several years and surgical interventions may be necessary during parts of this process in order to improve a patient's function and appearance. ${ }^{9}$ These 


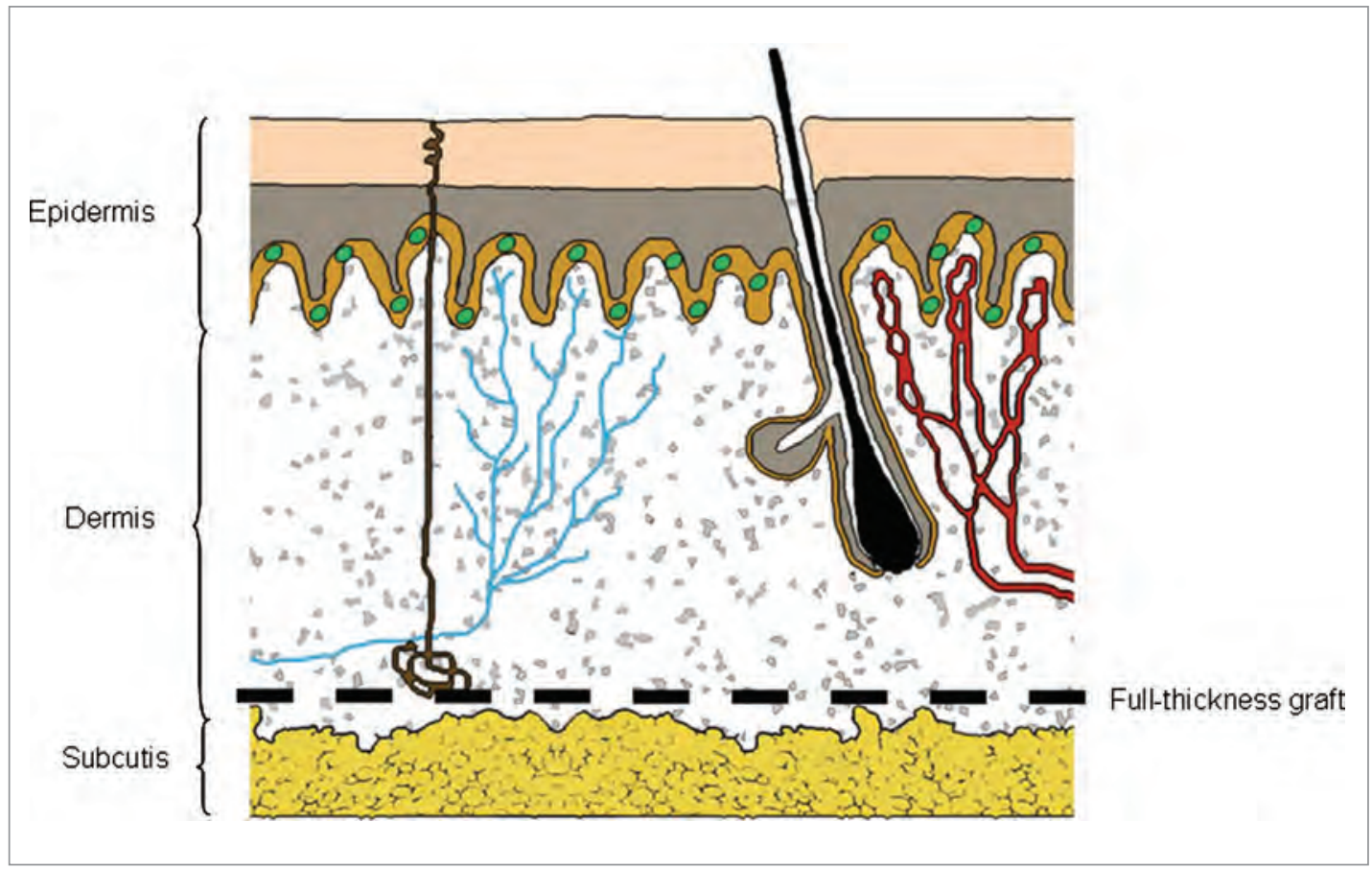

Figure 6-4. The skin in cross section indicating the depth of a full-thickness graft.

types of clinical problems can especially be seen in burn injuries to the hands, due to the large flexibility and mobility of the hand. It is often initially necessary to debride and excise deeper hand-burns and to cover the healthy bleeding wounds with superficial skin grafts in order to avoid secondary infections and contractive scarring with reduced hand function. Further corrective surgery may still be required later, but the early excision of the dead tissue is very important as it significantly enhances the chances of good hand function (Figure 6-5). ${ }^{13}$

\section{Clinical Management of Wounds}

Modern wound-healing treatments consist of debridement, negative pressure wound therapy, topical growth factors, the use of bio-engineered tissue, reconstructive wound-closure techniques (skin grafts, local flaps, pedicle flaps and microsurgical free flaps), and hyperbaric oxygen. It is important to have at least one of the physicians on the multidisciplinary wound team familiar with modern wound-care techniques. Debridement is the basis of all wound-healing strategies. Debriding a wound is defined as removing necrotic tissue, foreign material, and bacteria from an acute or chronic wound, all of which inhibits the wound healing. ${ }^{12}$ An acute wound has yet to progress through the sequential stages, a chronic wound has become "stuck" in one of the wound-healing stages. The advent of negative pressure wound therapy has reduced the number of non-healing wounds. The negative pressure device can provide rapid formation of granulation tissues and its ability to decrease edema helps prepare the wound for simple wound-closure techniques. ${ }^{14}$

\section{Pre-debridement Assessment}

The goal of treating any type of wound is to create an environment that is conductive to normal and timely healing. The process begins with the identification of a correct diagnosis of the wounds' etiology and continues with optimizing the patient's medical condition, including blood flow to the wound site. A proper wound assessment before debridement is essential, the origin and age of the wound should be determined, the patient's general condition (nutrition, smoking, local circulation, etc.) must also be taken into 


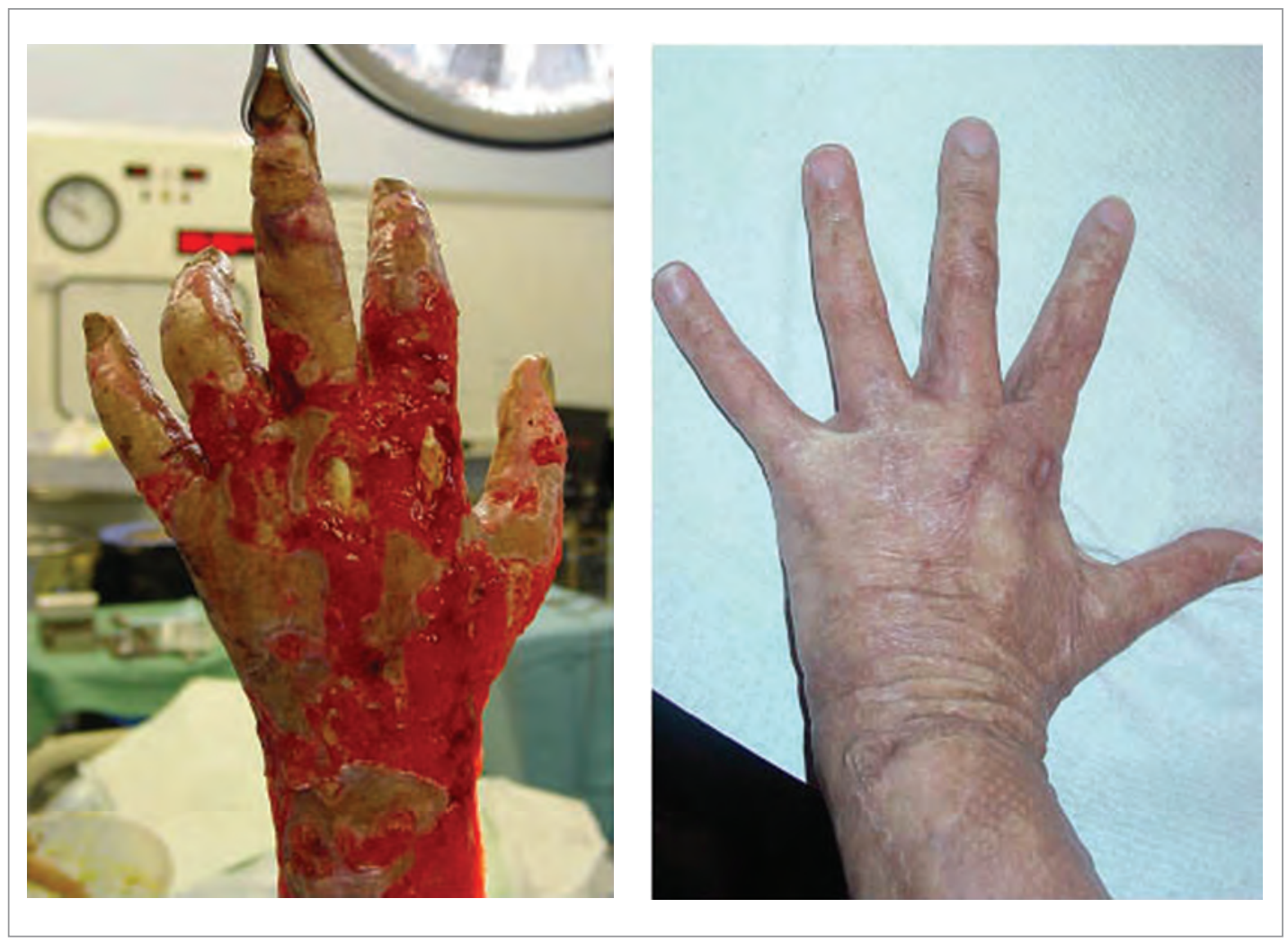

Figure 6-5. Deeply burnt hand (left) with exposed tendons before debridment and six months later after excision and skin grafting with meshed split-skin grafts.

account and a careful medical history should be obtained to identify any possible wound-healing inhibiting medical conditions. It is also clearly important to understand the extent of a wound, specifically with regards to wound depth and the involvement of deeper tissue, e.g., tendons and bone. An underlying osteomyelitis could feed a wound with bacteria if undiscovered. ${ }^{15}$ Magnetic resonance imaging (MRI) is today the gold standard way to diagnose osteomyelitis. An infected tendon and fascia can, in the same way, be a focus of infection. The wound-healing process and the take of a skin graft may be disturbed if the bacterial concentration on a wound is higher than $10^{5}$ per gram of tissue. A further increase of the bacterial load could spread from a local superficial infection to a systemic one which leads to septicemia. The application of topical antibiotics such as silver sulfadiazine, mafenide acetate, and silver nitrate all help to lower the bacterial count and reduce the risk of sepsis and can these be used before wound debridement. ${ }^{16,17}$

\section{Debridement}

Different debridement techniques include surgery, topical agents, and bio-surgery. The most important surgical step in treating any wound is to perform adequate debridement to remove all foreign material and unhealthy or non-viable tissue until the wound edges and base consist only of normal, soft, well-vascularized healthy tissue. ${ }^{12}$ Only an atraumatic surgical technique (sharp dissection, skin hooks, bipolar cautery, etc.) should be used in order to avoid damaging the underlying healthy tissue. ${ }^{18}$ This underlying healthy tissue will become the basis for the wound-healing progression. A chronic wound has to be converted by debridement to an acute wound so that it can then proceed through the normal healing phases. Frequent debridements remove the inhibitors of wound healing such as metalloproteases, including the collagenase matrix metalloproteinase 1 and 8 and elastase and it allows the growth factors to function more 
effectively. ${ }^{19}$ An immediate debridement is necessary when a necrotizing fasciatis or an ascending cellulitis occurs in conjunction with a wound. No other treatment could achieve bacterial control in such a wound status. Biological debriding agents such as maggots are an effective alternative to surgical debridement in patients who cannot go to the operating theatre for medical reasons. The maggots secrete enzymes that dissolve necrotic tissue and the biofilm that surrounds bacteria. This forms a nutrient-rich liquid that larvae can feed on. They are placed on wounds and covered with a semipermeable dressing. Debridement by maggots is painless but the sensate patient can feel the larvae moving. Importantly maggots help to sterilize wounds because they consume all bacteria regardless of their resistance to antibiotics including methicillin-resistant Staphylococcus aureus (MRSA). ${ }^{20-23}$

\section{Post-debridement Treatment}

After debridement a clear, well-vascularized wound should be kept in the optimal environment for healing (moist, clean, and vascularized) in order to enable the use of growth factors. Moist healing has been shown to be far more rapid than healing under an eschar or in other dry conditions. In this environment, the wound base can support and promote successful collagen deposition, angiogenesis, epithelialization, and wound contracture; the result should be the formation of healthy red granulation tissue with neoepithelialization at the borders. Epithelializing wounds are characterized by a pink neoepithelium that usually creeps in from the edges. ${ }^{12}$ A well-vascularized wound should, after debridement, heal by secondary intention or accept a skin graft. $^{24-26}$ Other surgical wound-closure techniques may also be required, e.g., flaps, all depending on the wound's location and extent. Exposed bone should if possible be covered with vascularized tissue, which is transferred into the wound in conjunction with the debridement. Preferably should a muscle-fatskin flap be used in order to heal the wound defect, as well as to help the bone tissue "fight" a threatening osteomyelitis (Figure 6-6).

\section{Dressings of Wounds}

There is no single dressing suitable for all types of wounds and often a number of different dressing types will be needed throughout the healing process. Dressings containing silver have returned in advanced wound care and are found used in conjunction with many products. ${ }^{27,28}$ Silver ions kill a broad spectrum of bacteria including methicillin-resistant Staphylococcus aureus (MRSA), Vancomycin-resistant Enterococcus, and Pseudomonas aeruginosa. ${ }^{12}$
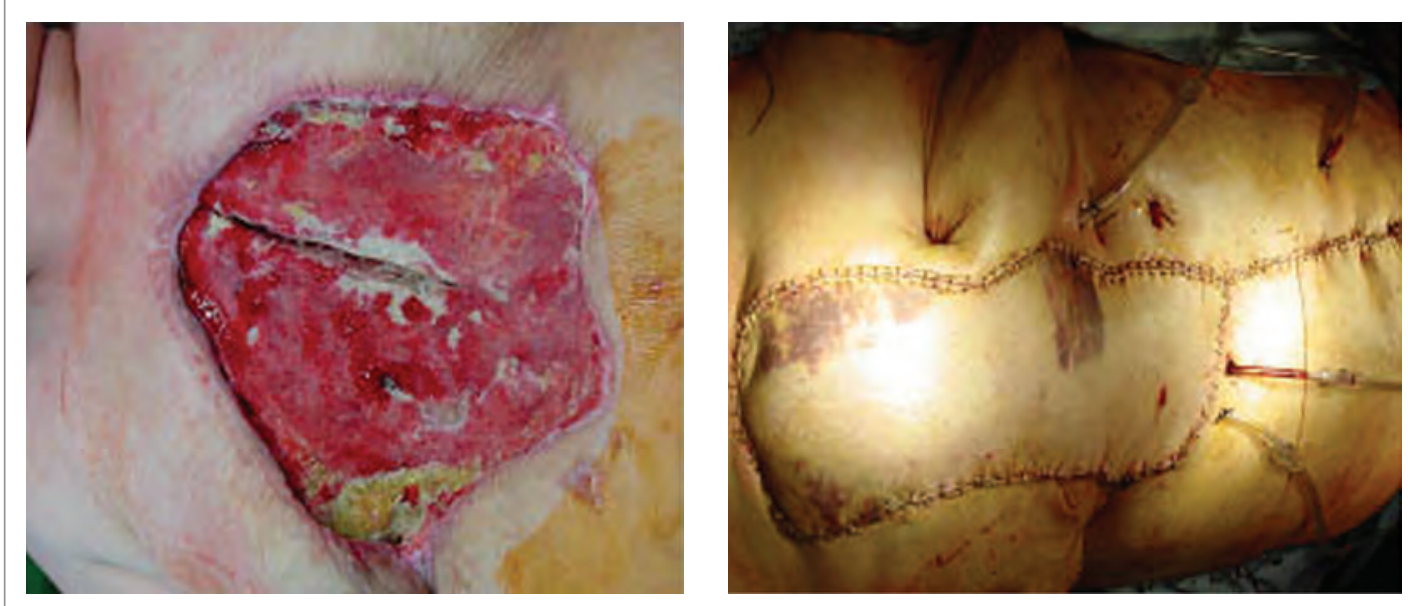

Figure 6-6. Chronic wound with osteomyelitis and exposed bone (sternum) after heart surgery (left). Debridment and wound closure with a pedicled musculo-cutaneus rectus abdominis flap (right). 


\section{Modern Skin Engineering}

Tissue engineering is an interdisciplinary scientific field that combines the principles of life science and engineering toward the development of biologic substitutes that will serve to restore, maintain, or improve tissue function. ${ }^{29}$ First, specific cells must be harvested, isolated, and expanded in tissue culture. The second component of tissue engineering focuses on the scaffold for tissue structure. Collaboration with biomedical engineers is critical for the development of novel scaffolds that will have the optimal combination of immunological compatibility, sufficient mechanical strength, and biodegradability (Figure 6-7). Third, the implanted construct should be incorporated into the healing tissue helping to restore structure and function. ${ }^{10}$ Various tissues have been engineered but the most developed are skin substitutes and a number of these produces have US/FDA approval and are currently available. ${ }^{2}$ The need for skin grafting has been the driving force behind the development of these skin substitutes. ${ }^{11}$ The skin is the largest single organ of the human body and although composed of only two specialized tissue layers, it remains a reconstructive challenge in many cases when compromised. The philosophy of replacing like with like has contributed to the development of the treatment strategies used today. The simplest treatment is secondary closure, which is when a wound is left to heal spontaneously. This does not always lead to a good functional and esthetic result and more complex tissue reconstruction may be necessary. Advanced type of tissue

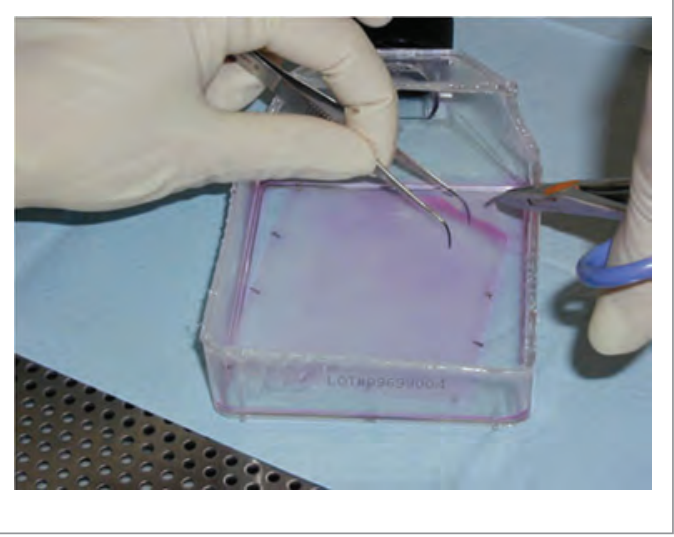

Figure 6-7. Preparation of a bio-engineered skin substitute. reconstruction in the form of distant-free tissue transfer can lead to superior functional results, but sets large demands on the patient and the surgical team. A large wound area due to its size may not be possible to treat with the patients' own tissue. A layer of tissue, which is mechanically similar to the original skin over a reconstruction site, has to be used in order to complete the reconstruction and to avoid failure. This has made bioengineered skin substitutes a solution that has received much attention lately. Skin substitutes are a heterogeneous group of substances that aid in the temporary or permanent closure of many types of wounds. Depending on wound and product characteristics, different skin substitutes may be chosen. Artificial skin substitutes, products of tissue engineering, consist of microengineered, biocompatible, polymer matrix in combination with cellular, and/or extracellular elements such as collagen. ${ }^{30}$ An ideal skin substitute should possess the physical characteristics and function of normal skin while healing takes place. However, no perfect or ideal skin substitute yet exists. ${ }^{2}$

\section{Characteristics and Clinical Use of Skin Substitutes}

Skin substitutes are a heterogeneous class of therapeutic devices that vary in their biology and application. Although there is no single perfect skin substitute, certain characteristics can be considered when evaluating alternatives. A long shelf-life and easy storage makes the product readily available. The substitute should be easy to prepare and apply without intensive training. Flexibility of thickness allows the product to be tailored to every type of wound. The product should be able to withstand a hypoxic wound bed and have a degree of resistance to infection in order to allow relatively ischemic tissues to be candidates for application. The ideal skin substitute should have resistance to tensile forces and provide permanent and longterm wound stability. It should reproduce both components of the skin (epidermis and dermis) and provide no antigenicity that could compromise the graft or host or present difficulties with future applications. ${ }^{2}$ Because no single product meets all these criteria, each patient case requires careful evaluation before choosing the appropriate treatment. Although many acute and chronic wounds may benefit from a tailored 
multidisciplinary approach that utilizes one or more of the products mentioned, each patient should be evaluated for other possible therapies before the use of skin substitutes. Adequate assessment of patient-related factors, surgical debridement, and infection control will first have to be performed. Different techniques such as local or regional flaps or microvascular (free tissue) transplantation should be considered and the incorporation of a skin substitute can be included in the patient's treatment plan. If a patient is not considered a candidate for wound or defect reconstruction, creative applications of skin substitute technologies may not only significantly benefit a patient, but also be the only option for wound closure. ${ }^{2}$

\section{Types of Skin Substitutes}

Xenografts are tissues transplanted from one species onto another species, used as a temporary graft (e.g., frog skin and lizard skin). Porcine products are the most commonly used xenografts today. ${ }^{3,4}$ Permacol and OASIS are among the currently available products. ${ }^{31,32}$

Allografts are grafts transplanted between genetically non-identical individuals of the same species. Most human skin substitute allografts come from cadaveric sources. Allografts fall into three categories: epithelial/epidermal, dermal, and composite (epidermal and dermal). Within these three categories, they may be acellular, cellular/living, or cellular/nonliving. AlloDerm is a commercial available acellular dermal allograft that was initially developed for skin defects, but it has also been used on burns and soft tissue replacement. ${ }^{33-35}$ This product retains dermal elements and the basement membrane allowed keratinocytes to migrate into the material. A subsequent split-thickness graft or cultured keratinocyte graft is added after neovascularization of the neodermis (Figure 6-8) for epidermal cover. Clinical use of acellularized human cadaveric dermis and ultra-thin skin grafts has shown good clinical results in face, hand, and foot burns. ${ }^{33-35}$ Graftjacket, Neoform, and DermaMatrix are further acellular dermal allografts available. ${ }^{36,37}$ ICX-SKN, TransCyte (also known as Dermagraft$T C$ ) and Dermagraft are cellular dermal allografts which use a scaffold of dermal collagen that is seeded with neonatal fibroblasts to stimulate cells within the host's wound to promote healing. ${ }^{38-44}$

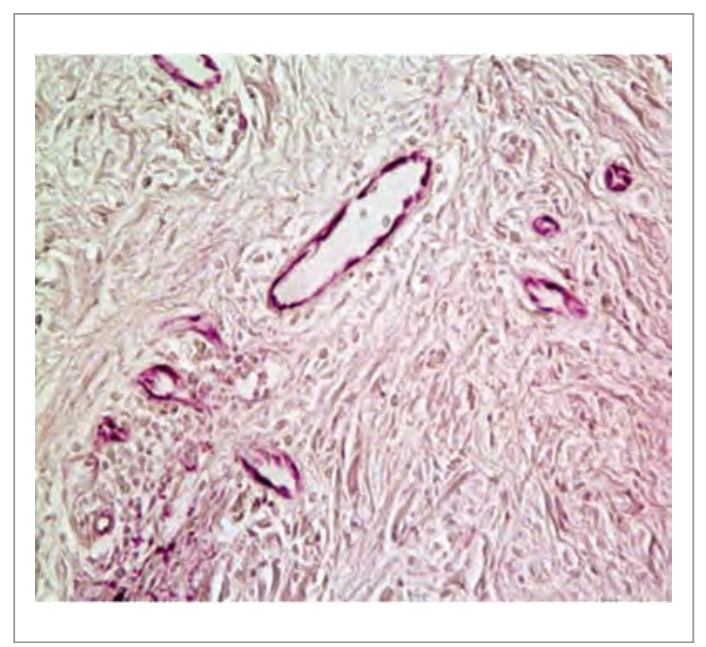

Figure 6-8. Histology from biopsy showing a neodermis with ingrowth of capillaries, collagen, and fibroblasts after use of a cell free dermal substitute.

Composite allograft products are the most advanced and closest products to living skin that are currently commercially available. Apligraft and Orcelare are the currently available products. Apiligraf has been used in the treatment of epidermolysis bullosa (EB). In a study of nine patients with 96 sites of skin loss, $90-100 \%$ healing was observed by 5-7 days with clinically normal appearing skin in place by days $10-14{ }^{45,46}$ OrCel, a composite bilayer produce with neonatal keratinocytes impregnated onto a coated nonporous sponge composed of type I bovine collagen has also been used for wound coverage after contracture release in EB patients. ${ }^{47,48}$ The FDA has approved its use for reconstruction or treatment of recessive dystrophic EB of the hands and skin graft donor sites in these patients. Studies evaluating its use in chronic venous and diabetic lower extremity ulcers are ongoing.

Autografts are tissues grafted to a new position on the same individual. They are commonly divided into three main categories: ${ }^{2}$

(1) Split-thickness skin grafts (STSGs) which contain the epidermis and a variable thickness of the upper layers of dermis, leaving the remaining layers of dermis in place to heal by secondary epithelialization from the wound edges and keratinocytes within the adnexa of the deeper dermis.

(2) Full-thickness skin grafts (FTSGs) which contain the epidermis and the entire dermis. ${ }^{49}$ These types of grafts are preferred in areas 
where significant scarring or contracture of the grafts would provide harmful esthetic or functional consequences. Because of the limited supply of FTSG donor sites they are usually reserved for reconstructing wounds of the head, neck, hands, and genitals.

(3) Cultured autologous skin substitutes which are frequently referred to as cultured epidermal autografts (CEAs). This nomenclature includes epidermal grafts and excludes dermal/epidermal grafts. The CEAs are grafted onto a wound and the healing of the new epidermis is initiated (Figure 6-9). Epicel and Laserskin are among the currently available products. ${ }^{50,51}$ Cultured skin substitute (CASS) is a CEA with the addition of a cultured autologous dermal layer, making it a more anatomically correct skin substitute. This product is still in clinical trials but it does in theory represent the most advanced autologous skin substitute available. The product is created by culturing autologous fibroblasts and keratinocytes with collagen and glycosaminoglycan substrates. ${ }^{52,53}$

A synthetic monolayer substitute Suprathel is a monolayer acellular synthetic dressing which has proven to decrease pain when used on donor sites. ${ }^{54,55}$

Synthetic biolayer substitutes are acellular products engineered without allogenic cells, they function as dermal templates and promote in growth of host tissues to repair defects or create a neodermis. After in growth, skin grafting can be performed on top of the new dermis. They also contain a removable silicone epidermal layer

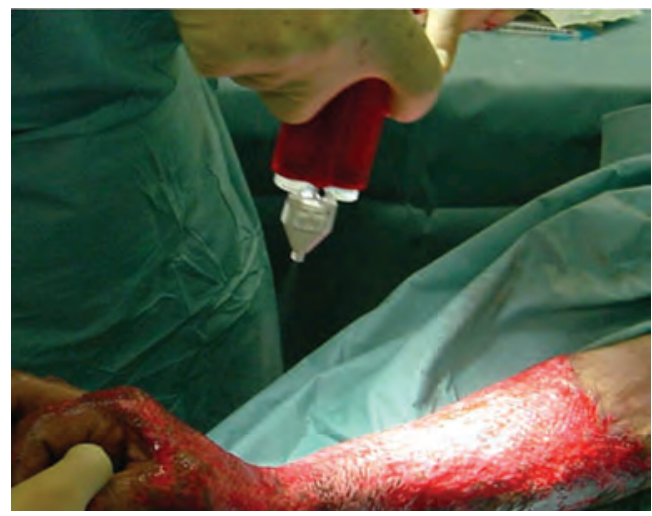

Figure 6-9. Spraying of cultivated cells onto dermal skin. to help protect the wound from moisture loss and contamination. Commercially available products are Biobrane and Integra. Biobrane is a biosynthetic skin substitute consisting of a bilaminate membrane of nylon mesh bonded to a thin layer of silicone, which is, coated with porcine type 1 collagen-derived peptides (dermal analogue). The silicone layer functions as temporary epidermis. ${ }^{56-58}$ Integra Bilayer Matrix Wound Dressing is a synthetic bilayer acellular skin substitute composed of an outer silastic sheet (epidermal analogue) with a matrix composed of bovine collagen and glycosaminoglycan (dermal analogue). ${ }^{59-67}$ The silastic sheet provides temporary cover before skin grafting is performed.

\section{What Does the Future Hold in Modern Skin Engineering?}

The wound-healing treatments with debridement remain very important. Infection control is vital for any healing. None of the available skin substitutes has been shown to be superior to autologous split-skin grafting (Figure 6-10). Existing substitutes do also have problems which include graft take, infection, immune and allergic reactions, and the need for a second procedure. We can today cultivate keratinocytes, fibroblasts as well as melanocytes in vitro and the cultivated cells are transplanted onto patients in different ways and in combination with skin substitutes, in order to facilitate wound healing and to provide patients with better esthetic and functional results (Figures 6-11, 6-12). The skin cannot regenerate itself and it

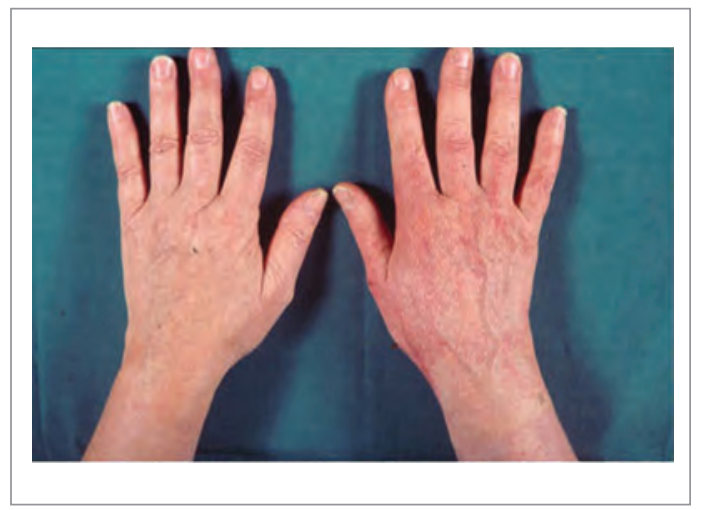

Figure 6-10. Late result of skin-grafted right hand compared to noninjured left hand. 


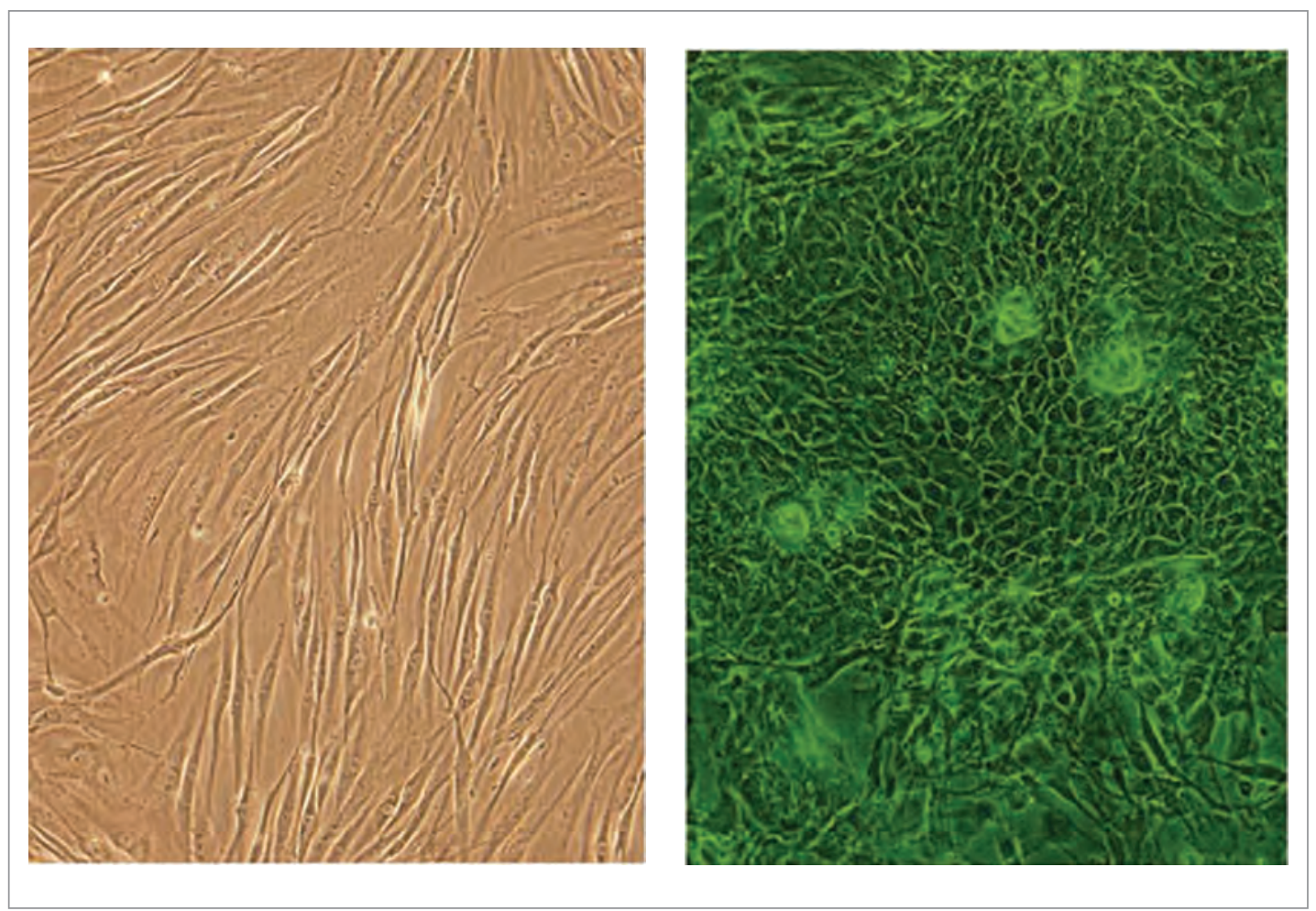

Figure 6-11. Cultivated Fibroblasts (left) and Keratinocytes (right) in vitro.
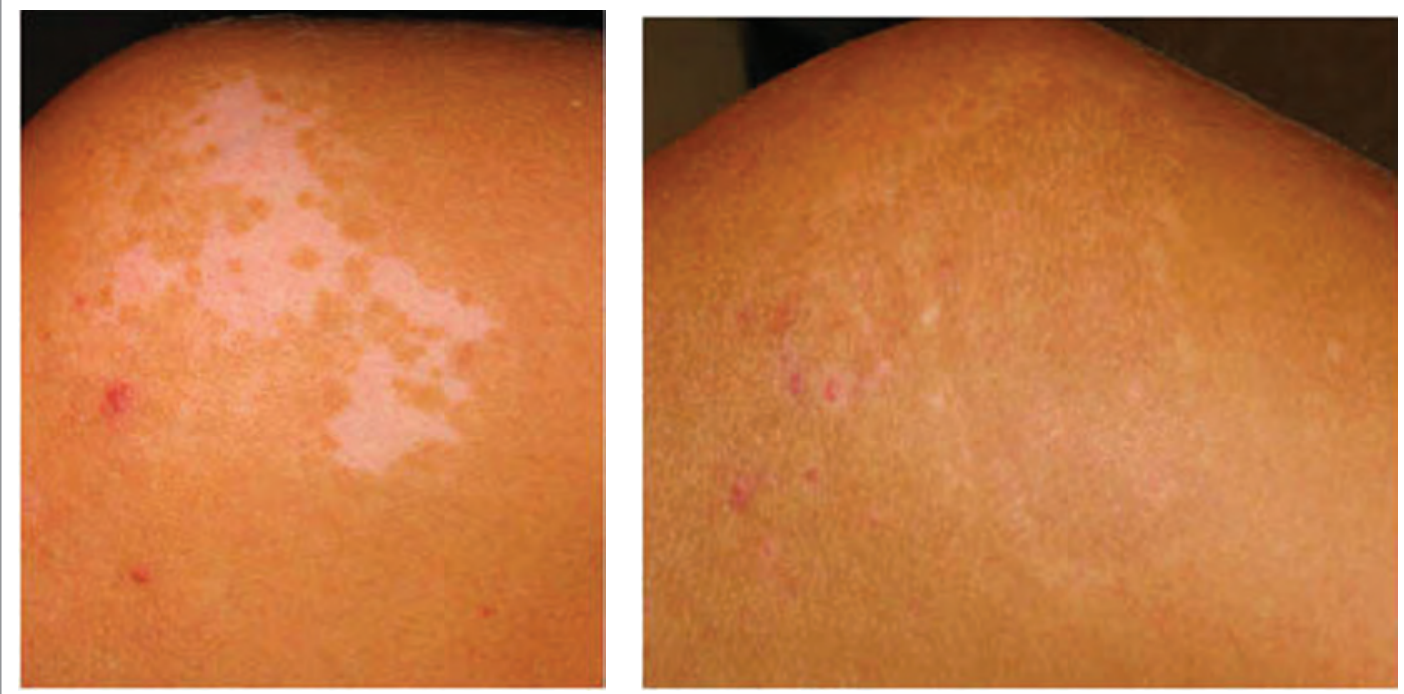

Figure 6-12. Vitiligo, before and after grafting of cultivated melanocytes. 
does heal with scarring which sometimes contracts severely. The future involves further understanding of the wound-healing mechanisms as well as further discoveries of the different functions of the different skin cells. The discovery of plasticity of cells (cells ability to transdifferentiate) may also influence the development of new types of skin substitute products with no antigenicity. ${ }^{68-73}$ The "key" to the stimulation of regeneration of the skin could reduce/eliminate skin scarring and provide us with better protection against micro-organisms which continue to threaten our existence.

\section{References}

1. Rudolph R, Ballantyne DL. Skin grafts. In: McCarthy J (ed). Plastic Surgery: Vol 1 General Principles. Philadelphia, PA: WB Saunders, 1990:221-25.

2. Shores JT, Gabriel A, Gupta S. Skin substitutes and alternatives: a review. Adv Skin Wound Care. September 2007; Vol. 20 No. 9. PP. 493-508.

3. Piccolo N, Piccolo-Lobo M, and Piccolo-Daher M. Use of frogskin as a temporary biological dressing, Proc Am Burn Assoc. 1992;24.

4. Chiu T, Burd A. "Xenograft" dressing in the treatment of burns. Clin Dermatol. 2005;23:419-23.

5. Bhishagratna K. The Sushruta Samhita: An English Translation Based on Original Texts. Cosmo Publications 2006.

6. Spencer WG. Celsus De Medicina, with English translation. Vol. 3. Cambridge, MA: Harward University press. 1938.

7. Balch CM, Marzoni FA. Skin transplantation during the pre-Reverdin era, 1804-1869. Surg Gynecol Obstet. 1977;144:766.

8. Reverdin JL. Greffes epidermiques; experience faite dans le service de M. le docteur Guyon, a l'Hopital Necker, pendant 1869. Bull Soc. Imperiale Chir. Paris Series 2, Vol.10, published in 1870 .

9. Peacock EE, Cohen IK. Wound healing. In: McCarthy J (ed). Plastic Surgery: Vol 1 General Principles. Philadelphia, PA: WB Saunders, 1990;161-178.

10. Chong AKS, Chang J. Tissue Engineering for the Hand Surgeon. A Clinical Perspective. J Hand Surg. March 2006;31A:3.

11. Mooney DJ, Mikos AG. Growing new organs. Sci Am. 1999;280:60-65.

12. Attinger CE, Janis JE, Steinberg J, Schwartz J, Al-Attar A, Couch K. Clinic approach to Wounds: Debridement and Wound Bed Preparation Including the Use of Dressings and Wound-Healing Adjuvants. Plastic and Reconstructive Surgery. Clinical Approach to Wounds. June Supplement 2006;117:7S.

13. Zellweger G. Die Behandlung Der Verbrennungen. 1985;118-121.

14. Defranzo AJ, Argenta LC, Marks M, et al. The use of vacuum-assisted closure therapy for the treatment of lower-extremity wound with exposed bone. Plast Reconstr Surg. 2001;108:1184.
15. Grayson ML, Gibbons GW, Balogh K, et al. Probing to bone in infected pedal ulcers: A clinical sign of osteomylitis in diabetic patients. JAMA. 1995;273:721.

16. Fox CL. Silver sulfadiazine, a new topical therapy for Pseudomonas in burns. Arch Surg. 1968;96:184.

17. Kucan JO, Robson MC, Heggers JP, et al. Comparison of silver sulfadiazine, povidone-iodine and physiological saline in the treatment of chronic pressure ulcers. J Am Geriatr Soc. 1981;29:232.

18. Edgerton MT. The Art of Surgical Technique, Baltimore: Williams \& Wilkins; 1988.

19. Trentgrove NJ, Stacey MC, Macauley S, et al. Analysis of the acute and chronic wound environments: The role of proteases and their inhibitors. Wound Repair Regen. 1999;7:442.

20. Courtenay M, Church JC, Ryan TJ. Larva therapy in wound management. J R Soc Med. 2000;93:394.

21. Sherman RA, Hall MJ, Thomas S. Medicinal maggots: An ancient remedy for some contemporary afflictions. Ann Rev Entomol. 2000;45:55.

22. Wollina U, Karte K, Herold C. Biosurgery in wound healing: The renaissance of maggot therapy. J Eur Acad Dermatol Venerol. 2000;14:285.

23. Sherman RA, Sherman J, Gilead L, et al. Maggot therapy in outpatients. Arch Phys Med Rehab. 2001;81:1226.

24. Krizek TJ, Robson MC. The evolution of quantitative bacteriology in wound management. Am J Surg. 1975;130:579.

25. Robson MC, Heggers JP. Delayed wound closure based on bacterial counts. J Surg Oncol. 1970;2:379.

26. Robson MC, Heggers JP. Bacterial quantification of open wounds. Mil Med. 1969;134:19.

27. Tredget EE, Shankowsky HA, Goeneveld A, et al. A matched-pair, randomised study evaluating the efficacy and safety of Acticoat silver coated dressing for treatment of burn wounds. J Burn Care Rehabil. 1998;19:531.

28. Yin HQ, Langford R, Burrell RE. Comparative evaluation of the antimicrobial activity of Acticoat antimicrobial dressing. J Burn Care Rehabil. 1999;20:195.

29. Langer R, Vacanti JP. Tissue engineering. Science. 1993;260:920-926.

30. Enoch S, Grey JE, Harding KG. ABC of wound healing. Recent advances and emerging treatments. BMJ. 22 April 2006;332:962-965.

31. Harper C. Permacol: clinical experience with a new biomaterial. Hosp Med. 2001;62:90-5.

32. Hodde JP, Ernst DM, Hiles MC. An investigation of the long-term bioactivity of endogenous growth factor in OASIS Wound Matrix. J Wound Care. 2005;14:23-5.

33. Wainwright DJ. Use of an acellular allograft dermal matrix (Alloderm) in the management of full-thickness burns. Burns. 1995;21:243-8.

34. Munster AM, Smith-Meek M, Shalom A. Acellular allograft dermal matrix: immediate or delayed epidermal coverage? Burns. 2001;27:150-3.

35. Sheridan R, Choucair R, Donelan M, Lydon M, Petras L, Tomkins R. Acellular allodermis in burns surgery: 1-year results of a pilot trial. J Burn Care Rehabil. 1998;19:528-30.

36. Brigido SA, Boc SF, Lopez RC. Effective management of major lower extremity wounds using an acellular regenerative tissue matrix: a pilot study. Orthopedics. 2004;27(Suppl):s145-9.

37. Schoepf C. Allograft safety: efficacy of the tutoplast process. Implants- Int Magazine Oral Implant. 2006;7.

38. Lukish JR, Eichelberger MR, Newman KD, et al. The use of a bioactive skin substitute decreases length of stay for pediatric burn patients. J Pediatr Surg. 2001;36:1118-21. 
39. Demling RH, Desanti L. Management of partial thickness facial burns (comparison of topical antibiotics and bioengineered skin substitutes) Burns. 1999;25:256-61.

40. Mansbridge J, Liu K, Patch R, Symons K, Pinney E. Three-dimensional fibroblast culture implant for the treatment of diabetic foot ulcers: metabolic activity and therapeutic range. Tissue Eng. 1998;4:403-14.

41. Harding KG, Moore K, Phillips TJ. Wound chronicity and fibroblast senescence-implications for treatment. Int Wound J. 2005;2:364-8.

42. Boyd M, Flasza M, Johnson PA, Roberts JS, Kemp P. Integration and Persistence of an investigational human living skin equivalent (1CX-SKN) in human surgical wounds. Regen Med. 2007;2:369-76.

43. Bello YM, Falabella AF, Eaglstein WH. Tissue-engineered skin. Current status in wound healing. Am J Clin Dermatol. 2001;2:305-13.

44. Purdue GF, Hunt JL, Still JM Jr. et al. A mulitcenter clinical trial of a biosynthetic skin replacement, Dermagraft-TC, compared with cryopreserved human cadaver skin for temporary coverage of excised burn wounds. $J$ Burn Care Rehabil. 1997;18(1 Pt 1):52-7.

45. Fivenson DP, Scherschun L, Cohen LV. Apligraft in the treatment of severe mitten deformity associated with recessive dystrophic epidermolysis bullosa. Plast Reconstr Surg. 2003;112:584-8.

46. Fivenson DP, Scherschun L, Choucair M, Kukuruga D, Young J, Shwayder T. Graftskin therapy in epidermolysis Bullosa. J Am Acad Dermatol. 2003;48:886-92.

47. Still J, Glat P, Silverstein P, Griswold J, Mozingo D. The use of a collagen sponge/living cell composite material to treat donor sites in burn patients. Burns. 2003;29:837-41.

48. Sibbald RG, Zuker R, Coutts P, Coelho S, Williamson D, Queen D. Using a dermal skin substitute in the treatment of chronic wounds secondary to recessive dystrophic epidermolysis bullosa: a case series. Ostomy Wound Manage. 2005;51(11):22-46.

49. Wright KA, Nadire KB, Busto P, Tubo R, McPherson JM, Wentworth BM, Alternative delivery of keratinocytes using a polyurethane membrane and the implications for its use in the treatment of full-thickness burn injury. Burns. 1998;24:7-17.

50. Carsin H, Ainaud P, Le Bever H, et al. Cultured epithelial autografts in extensive burn coverage of severely traumatized patients: a five year single- centre experience with 30 patients. Burns. 2000;26:379-87.

51. Lobmann R, Pittasch D, Muhlen I, Lehnert H. Autologous human keratinocytes cultured on membranes composed of benzyl ester of hyaluronic acid for grafting in nonhealing diabetic foot lesions: a pilot study. J Diabetes Complications. 2003;17:199-204.

52. Harriger MD, Warden GD, Greenhalgh DG, Kagan RJ, Boyce ST. Pigmentation and microanatomy of skin regenerated from composite grafts of cultured cells and biopolymers applied to full-thickness burn wounds. Transplantation. 1995;59:702-7.

53. Boyce ST, Goretsky MJ, Greenhalgh DG, Kagan RJ, Rieman MT, Warden GD. Comparative assessment of cultured skin substitutes and native skin autograft for treatment of full-thickness burns. Ann Surg. 1995;222:743-52.

54. Schwarze H, Kuntscher M, Uhlig C, et al. Suprathel, a new skin substitute, in the management of donor sites of split-thickness skin grafts: Results of a clinical study. Burns. 2007; E-pub:doi: 10.1016/j.burns. 2006. 10.393 .
55. Banes AJ, Compton DW, Bomhoeft J, et al. Biologic, biosynthetic, and synthetic dressings a temporary wound covers: a biochemical comparison. J Burn Care Rehabil. 1986;7:96-104.

56. McHugh TP, Robson MC, Heggars JP, Phillips LG, Smith DJ Jr, McCollum MC. Therapeutic efficacy of Biobrane in partial- and full-thickness thermal injury. Surgery. 1986;100:661-4.

57. Feldman DL, Rogers A, Karpinski RH. A prospective trial comparing Biobrane DuoDERM and Xeroform for skin graft donor sites. Surg Gynecol Obstet. 1991;173:1-5.

58. Prasad JK, Feller I, Thomson PD. A Prospective controlled trial of Biobrane versus scarlet red on skin graft donor areas. J Burn Care Rehabil. 1987;8:384-6.

59. Grzesiak JJ, Pierschbacher MD, Amodeo MF, Malaney TI, Glass JR. Enhancement of cell interactions with collagen/gylcosaminoglycan matrices by RGD derivatization. Biomaterials. 1997;18:1625-32.

60. Stern R, McPherson M, Longaker MT.Histologic study of artifical skin used in the treatment of full-thickness thermal injury. J Burn Care Rehabil. 1990;11:7-13.

61. Komorowska-Timek E, Gabriel A, Bennett DC, et al. Artificial dermis as an alternative for coverage of complex scalp defects following excision of malignant tumours. Plast Reconstr Surg. 2005;115:1010-7.

62. Machens HG, Berger AC, Mailaender P, Bioartificial skin. Cells Tissue Organs. 2000;167:88-94.

63. Orgill DP, Straus FH 2nd, Lee RC. The use of collagenGAG membranes in reconstructive surgery. Ann NY Acad Sci. 1999;888:233-48.

64. Fitton AR, Drew P, Dickson WA. The use of a bilaminate artificial skin substitute (Integra) in acute resurfacing of burns: an early experience. Br J Plast Surg. 2001; 54:208-12.

65. Klein MB, Engrav LH, Holmes JH, et al. Management of facial burns with a collagen/glycosaminoglycan skin substitute-prospective experience with 12 consecutive patients with large, deep facial burns. Burns. 2005;31: 257-61.

66. Groos N, Guillot M, Zilliox R, Braye FM. Use of an artificial dermis (integra) for the reconstruction of extensive burn scars in children. About 22 grafts. Eur J Paediatr Surg. 2005;15:187-92.

67. Jeschke MG, Rose C, Angele P, Fuchtmeier B, Nerlich MN, Bolder U. Development of new reconstructive techniques: use of Integra in combination with fibrin glue and negative-pressure therapy for reconstruction of acute and chronic wounds. Plast Reconstr Surg. 2004;113:525-30.

68. Brazelton TR, Rossi FM., Kesher, GI, Blau, HM. From marrow to brain: expression of neuronal phenotypes in adult mice. Science. 2000;290:1775-1779.

69. Mezey E, Chandross KJ, Harta G, Maki RA, McKercher SR. Turning blood into brain: cells bearing neuronal antigens generated in vivo from bone marrow. Science. 2000;290:1779-1782.

71. Orlic D, Kajstura J, Chimenti S, Jakoniuk I, Anderson $\mathrm{SM}, \mathrm{Li} \mathrm{B}$, et al. Bone marrow cells regenerate infracted myocardium. Nature. 2001;410:701-705.

72. Sigurjonsson OE, Perreault MC, Egeland T, Glover JC. Adult human hematopoietic stem cells produce neurons efficiently in the regenerating chicken embryo spinal cord. Proc Natl Acad Sci USA. 2005;102:5227-5232.

73. Wurmser AE, Nakashima, K, Summers RG, Toni N, D, Amour KA, Lie DC, et al. Cell fusion-independent differentiation of neural stem cells to the endothelial lineage. Nature. 2004;430:350-356. 